\title{
Interrelationships between progesterone, 13,14-dihydro-15-keto PGF-2 $\alpha$ (PGFM) and LH in cyclic and early pregnant cows
}

\author{
T. J. Parkinson* and G. E. Lamming \\ AFRC Research Group on Hormones and Farm Animal Reproduction, University of Nottingham, \\ Faculty of Agricultural and Food Sciences, Sutton Bonington, Loughborough, Leics LE12 5RD, UK
}

\begin{abstract}
Summary. Plasma progesterone and LH secretion patterns were examined in 18 mature dairy cows during the oestrous cycle and after insemination. Blood samples were collected every $15 \mathrm{~min}$ for $8 \mathrm{~h}$ per day on Days $3,5,6,7,8,9,10,12,14,16,17,18,19,20$ and 21 of the oestrous cycle, then, in the same cows, at the same times during early pregnancy. PGF-2 $\alpha$ secretion rates (as determined by plasma PGFM concentrations) were also monitored on Days 14,16 and the day of, or equivalent to, luteal regression. Mean daily plasma progesterone concentrations were similar until Day 16 in cyclic and pregnant cows, after which values in non-pregnant animals declined. Regression analysis indicated that progesterone concentrations were best described by a quadratic expression with fitted maximum values on Day 13 in non-pregnant animals but values increased linearly over the whole period to Day 21 in pregnant cows. The frequency, amplitude and area under the curve of LH episodes showed no significant differences between cyclic and pregnant animals. In pregnant cows, the amplitude and area under the curve of progesterone episodes increased linearly between Days 8 and 21, although no such increase occurred in cyclic cows. Low-level PGFM episodes were present in cyclic and pregnant cows on Days 14 and 16 after oestrus, and high amplitude episodes occurred in non-pregnant cows during luteal regression. Pregnant cows showed a significant depression of the amplitude, but not the frequency of episodes at the expected time of luteal regression. These results confirm that the corpus luteum of pregnancy secretes an increasing amount of progesterone per se and per unit of LH until at least Day 21 after mating. They further suggest that the corpus luteum of the cyclic cow may experience small episodes of PGF-2 $\alpha$ and be subjected to initial degenerative changes by Day 14 after oestrus, some time before the onset of definitive luteolysis.
\end{abstract}

Keyw'ords: early pregnancy; cow; $\mathrm{LH} /$ progesterone relationships

\section{Introduction}

The successful establishment of pregnancy in cattle requires a prolongation of the functional lifespan of the corpus luteum. It remains uncertain whether the corpus luteum of pregnancy exhibits any differences in the pattern of progesterone secretion from the cyclic corpus luteum before the time of the 'maternal recognition of pregnancy'. Many studies have compared circulating progesterone concentrations in cyclic and pregnant cattle, with diverse results. Some authors have found higher concentrations in pregnant animals, from soon after conception (blood plasma from Day 6; Henricks et al., 1971; Erb et al., 1976; or from Day 10: Lukaszewska \& Hansel, 1980;

\footnotetext{
*Present address: Department of Veterinary Surgery, University of Bristol, Langford House, Langford, Bristol BSI8 7DU, UK.
} 
Hansel, 1981; milk from Day 6: Bloomfield et al., 1986). Conversely, others have not observed any differences until the onset of luteolysis in cyclic animals. No divergences of plasma progesterone concentrations were observed before Day 13 in the studies of Shemesh et al. (1968), Pope et al. (1969), Robertson \& Sarda (1971), Sreenan \& Diskin (1983) and Roche et al. (1985). Similarly, no differences in milk progesterone concentrations were found until Day 12 (Lamming et al., 1989) or 13 (Bulman \& Lamming, 1978).

Hence, while it is clear that the embryo has an antiluteolytic effect at the time of maternal recognition of pregnancy (see Thatcher et al., 1989), it remains uncertain whether the embryo exerts any early luteotrophic effects. The purpose of this study was to determine whether, and at what stage, pregnant cows have significantly different endocrine patterns from cyclic animals. In particular, the magnitude of progesterone episodes secreted in response to episodes of $\mathrm{LH}$ was studied to elucidate the effects of early pregnancy upon luteal function.

\title{
Materials and Methods
}

\begin{abstract}
Animals and sampling protocol. Holstein $\times$ Friesian dairy cows which had calved at least 4 months previously were used to study the patterns of LH, progesterone and PGFM secretion in the cycle and early pregnancy. The investigation included a pilot study using 4 cows, followed by a further trial using 14 animals. In both parts of the experiment blood samples were collected throughout an oestrous cycle and the first 3 weeks of pregnancy, with a 'rest' period of one oestrous cycle between the two sampling periods. The cows were housed in stalls for the duration of the experiment. They had unrestricted access to water, and were fed hay ad libitum, with a supplement of a proprietary compound ration according to individual milk yield.

Oestrus was synchronized by intramuscular injection of $500 \mu \mathrm{g}$ cloprostenol (Estrumate, Coopers Animal Health, Crewe, UK) given twice, 11 days apart. On the day after the second dose of cloprostenol (Day 2), a jugular venous cannula was inserted and each animal was then inseminated with killed semen on Days 0 and 1 . The 3rd day after cloprostenol treatment (Day 0 ) was counted as the expected day of oestrus and 5-ml samples of jugular venous blood were collected from each cow every $2 \mathrm{~h}$ during Days $-1,0$ and $\mathrm{I}$ for $12 \mathrm{~h}$, for oestradiol and LH assay.

All the cows in the pilot study and 7 cows in the main experiment were sampled every $15 \mathrm{~min}$ for $8 \mathrm{~h}$ on Days 3,5 , $6,7,8,9,10$ and 12 . The remaining 7 cows had jugular cannulae inserted on Day 13 and these, together with the cows in the pilot study, were similarly blood sampled on Days 14, 16, 17, 18, 19, 20 and 21 . An additional $10 \mathrm{ml}$ blood were collected from Day 14 onwards by the same protocol, for the assay of plasma PGFM concentrations. The 7 cows sampled on Days 3 to 12 in the main investigation were not used after Day 14. Starting on Day 28 after the first induced oestrus, all cows were resynchronized by giving two further injections of cloprostenol. An identical protocol to that detailed above was then followed, with the exception that the cows were inseminated with live semen. Each animal remained in the same group during the second sampling period,

All cows in the preliminary and the main investigations had milk samples collected from them for progesterone determination from the day on which blood sampling ceased until the 28 th day after insemination. These data were used to obtain an early indication of pregnancy and of cycle normality. Pregnancy was confirmed by palpation of the uterus per rectum 42 days after insemination.
\end{abstract}

Hormone assays. Plasma progesterone concentrations were measured using the radioimmunoassay described by Haresign et al. (1975), with the modifications of Hunter et al. (1986). Samples taken on the same day, relative to the day of expected oestrus, from the sham inseminated (cyclic) and live inseminated (pregnant) animals were included in the same assay, to eliminate effects of assay variation. The inter-assay coefficients of variation over the 46 and 79 assays from the preliminary and main experiments were $20.1 \%$ and $16.6 \%$ respectively. The intra-assay coefficient was $5.9 \%$ and the limit of sensitivity, using a $100 \mu \mathrm{l}$ sample of plasma, was $0.09 \mathrm{ng} / \mathrm{ml}$.

Plasma LH concentrations were measured in samples collected from all cows on Days 6, 8 and 10 (relative to the day of the LH surge) and Days 12, 14,16, 18 and 19 (relative to the predicted day of oestrus). Concentrations were also measured in samples collected on Day 21 relative to the predicted day of oestrus in pregnant cows, and on the day of luteal regression in cyclic cows and those cows which were inseminated but not pregnant by Day 21 . The radioimmunoassay described by Webb et al. (1977) was used and the results are expressed as ng equivalents of NIH-LH$\mathrm{B} 9 / \mathrm{ml}$. The intra- and inter-assay coefficients of variation over 9 assays were $5.9 \%$ and $14.2 \%$ respectively and the limit of sensitivity, using a $100 \mu \mathrm{l}$ sample of plasma, was $0.37 \mathrm{ng} / \mathrm{ml}$.

Plasma oestradiol concentrations in pooled daily samples of plasma collected on Days $-1,0$ and 1 were measured using the radioimmunoassay of Glencross \& Pope (1981), with the modifications of Glencross et al. (1981). Over 2 assays, the intra- and inter-assay coefficients of variation were $6.9 \%$ and $16.7 \%$ respectively, and the limit of sensitivity, using a $4 \mathrm{ml}$ sample, was $1.41 \mathrm{pg} / \mathrm{ml}$.

Plasma PGFM concentrations were measured in samples collected from 4 cows on Days 14 and 16 of the cycle and pregnancy, and from all cows on the day of luteal regression or, in pregnant animals, the day of pregnancy equivalent to the day on which each cow had shown luteal regression in the previously studied cycle. The radioimmunoassay 
described by Kaker et al. (1984) and Alam \& Dobson (1986) was used. Over 16 assays, the limit of sensitivity, using a $500 \mu \mathrm{l}$ sample of plasma, was $53.3 \mathrm{pg} / \mathrm{ml}$ and the intra- and inter-assay coefficients of variation $7 \cdot 8$ and $14.5 \%$ respectively.

Finally, milk progesterone concentrations were measured using the radioimmunossay described by Gadsby $e t a l$. (1974) and modified by Bulman \& Lamming (1978). Intra- and inter-assay coefficients of variation over 11 assays were $8.5 \%$ and $18 \cdot 2 \%$ respectively, and the limit of sensitivity, using a $10 \mu \mathrm{l}$ sample was $2 \cdot 0 \mathrm{ng} / \mathrm{ml}$.

Analysis of data. Data were synchronized around the day of the LH surge. The time of the surge was determined either by detecting the surge itself, or by using the day of maximal oestradiol concentrations as a predictor of the $\mathrm{LH}$ surge, in those cows in which this occurred during the $12-\mathrm{h}$ period when no plasma samples were collected.

Data from the pilot and main studies were pooled. To ensure the validity of this manoeuvre, data from the two experiments were separately pooled by day of the cycle or pregnancy and then regressed against each other. The regression obtained was highly significant $(P<0.0001)$. Since there was no break in the plasma hormone profile at the point in the main study at which the groups changed, pooled data are used throughout this paper.

The day of luteal regression was defined as that on which mean daily plasma progesterone concentrations were significantly below those of the mid-luteal phase, but had not yet declined to values typical of the follicular phase. For each cow, whether cyclic or inseminated but non-pregnant, there was only one day on which this definition was met. The amplitude of LH episodes (as defined by the peak concentration minus the concentration at the preceding nadir), the area under the curve of each episode and the episode frequency were determined using the criteria of Goodman \& Karsch (1980) to define episodes. The frequency, maximum amplitude and area under the curve of progesterone episodes were determined using a modification of the criteria of Procknor et al. (1986) to define progesterone episodes, i.e. any elevation of concentration which lasted for at least $30 \mathrm{~min}$ and which was at least 3 times the intra-assay coefficient of variation above the preceding nadir. Analysis of LH and progesterone episodes was made for those days on which the concentrations of both hormones had been measured. Mean profiles of LH and progesterone episodes for each group were determined on each of the specified days. The percentage of LH episodes accompanied by episodes of progesterone, and vice versa, were determined and the interval between peak LH concentrations and the onset and peak values of progesterone episodes were calculated.

A PGFM episode was defined as an increase in concentration of at least $100 \mathrm{pg} / \mathrm{ml}$ above the preceding nadir, which remained elevated for at least 3 consecutive samples. The frequency, amplitude and area under the curve of PGFM episodes were calculated for each group of cows.

Statistical methods. Plasma progesterone concentration data and the magnitude of LH, progesterone and PGFM episodes were subjected to analysis of variance. Episode frequency data were subjected to regression analysis and analysis of deviance, making the assumption of a Poisson distribution. For all analyses, the factors used were the day relative to the $\mathrm{LH}$ surge and pregnancy status.

Mean daily plasma progesterone concentrations and the frequency and magnitude of LH and progesterone episodes were subjected to regression analysis, with respect to day, using linear and quadratic models. Differences of regression lines between groups were quantified using analysis of deviance.

\section{Results}

Data were obtained for 3 cyclic cows throughout Days 0 to 21, plus 5 animals from Days 0 to 12 and 4 from Days 14 to 21, making a total of 12 cows in this group. For pregnant cows, 4 animals provided data from Days 0 to 21 and 3 each for the periods between Days 0 and 12 and Days 14 to 21; a total of 10 animals. Data from 6 inseminated but non-pregnant animals were also available. Data from other animals were excluded due to lack of synchronization of oestrus or failure of subsequent luteal function. One inseminated but non-pregnant cow had elevated milk progesterone concentrations on Day 28, but was found to be barren on Day 42 . The remaining cows of this type showed a decline in progesterone concentrations by Day 21 .

\section{Mean daily progesterone concentrations}

Mean daily plasma progesterone concentrations, synchronized around the day of the LH surge, are shown for cyclic and pregnant cows in Fig. 1. Concentrations were higher in pregnant than in cyclic cows on Days 16, $17(P<0.05), 19,20$ and $21(P<0.01)$, and higher in inseminated, non-pregnant than cyclic cows on Days $16(P<0.01), 17(P<0.05), 20$ and $21(P<0.01)$. Concentrations were higher in inseminated, non-pregnant cows than in pregnant cows on Day 8 $(P<0.05)$. The luteal phase, calculated as the interval between the day of the LH surge and that of 


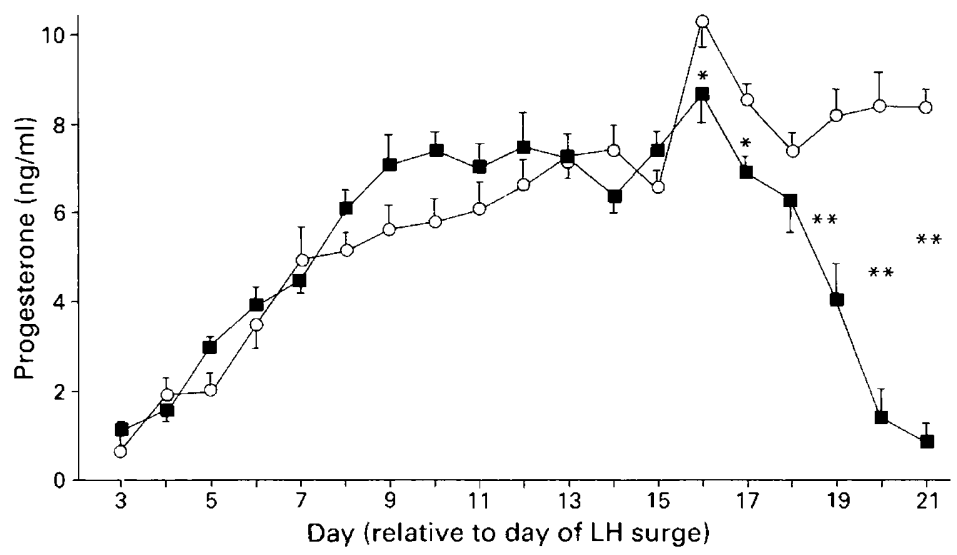

Fig. 1. Mean ( \pm s.e.m.) daily plasma progesterone concentrations in cyclic $\square-\mathbf{\square}(\mathbf{N}=12)$ and pregnant $O-O(N=10)$ cows, synchronized around the day of the LH surge. Differences between daily means are significant $\left({ }^{*} P<0 \cdot 05,{ }^{* *} P<0 \cdot 01\right)$.

Table 1. Coefficients of linear and quadratic regression equations describing the changes of plasma progesterone concentrations with time, between Days 3 and 17

\begin{tabular}{|c|c|c|c|c|c|c|c|}
\hline & \multicolumn{3}{|c|}{$\begin{array}{l}\text { Linear model } \\
(p=\mathrm{a} t+\mathrm{b})\end{array}$} & \multicolumn{4}{|c|}{$\begin{array}{l}\text { Quadratic model } \\
\left(p=\mathrm{c} t^{2}+\mathrm{d} t+\mathrm{e}\right)\end{array}$} \\
\hline & a & $\mathrm{b}$ & r.m.s. & $\mathrm{c}$ & d & e & r.m.s. \\
\hline Cyclic cows & 0.382 & $2 \cdot 131$ & $2 \cdot 557$ & -0.067 & 1.793 & $-4 \cdot 222$ & $1.471^{* * *}$ \\
\hline $\begin{array}{l}\text { Inseminated non-pregnant } \\
\text { cows }\end{array}$ & 0.421 & $2 \cdot 005$ & 3.002 & -0.054 & 1.509 & $-2 \cdot 570$ & $2 \cdot 217^{*}$ \\
\hline Pregnant cows & 0.553 & 0.439 & 2.527 & -0.027 & 1.099 & $-2 \cdot 130$ & $2 \cdot 372 \mathrm{NS}$ \\
\hline
\end{tabular}

$p=$ Plasma progesterone concentration $(\mathrm{ng} / \mathrm{ml}), t=$ time; i.e. days from the LH surge, r.m.s. $=$ residual mean squares.

The reduction in residual mean squares obtained by adding the quadratic term to the model is significant as indicated: ${ }^{*} P<0.05,{ }^{* * *} P<0.001$.

All regression equations, whether linear or quadratic, were significantly different from zero $(P<0.01)$.

luteal regression, was longer in inseminated non-pregnant cows than in cyclic animals $(20 \cdot 3 \pm 0 \cdot 27$ and $18.6 \pm 0.34$ days respectively; $P<0.05$ )

Regression analysis of the rates of rise of progesterone concentrations over Days 3 to 10 showed that these were similar in all three groups. The intercept term for inseminated non-pregnant cows was significantly greater than for other groups $(P<0.01)$. A similar regression analysis made for Days 10 to 17 indicated that cyclic cows exhibited no further increase in progesterone concentrations, while pregnant animals showed a significant $(P<0.01)$ linear increase with time over this period:

$$
p=3 \cdot 56+0 \cdot 296 t
$$

(where $p=$ plasma progesterone concentration $(\mathrm{ng} / \mathrm{ml}$ ) and $t=$ time; i.e. days after the $\mathrm{LH}$ surge).

Hence, an overall comparison of linear and quadratic regression lines for cyclic and inseminated non-pregnant cows between Days 3 and 17 showed that the quadratic expression accounted for a greater amount of the total variance in the data than did the linear model (cyclic, $P<0 \cdot 001$; inseminated non-pregnant, $P<0.05$; see Table 1). For pregnant cows, however, the quadratic term 

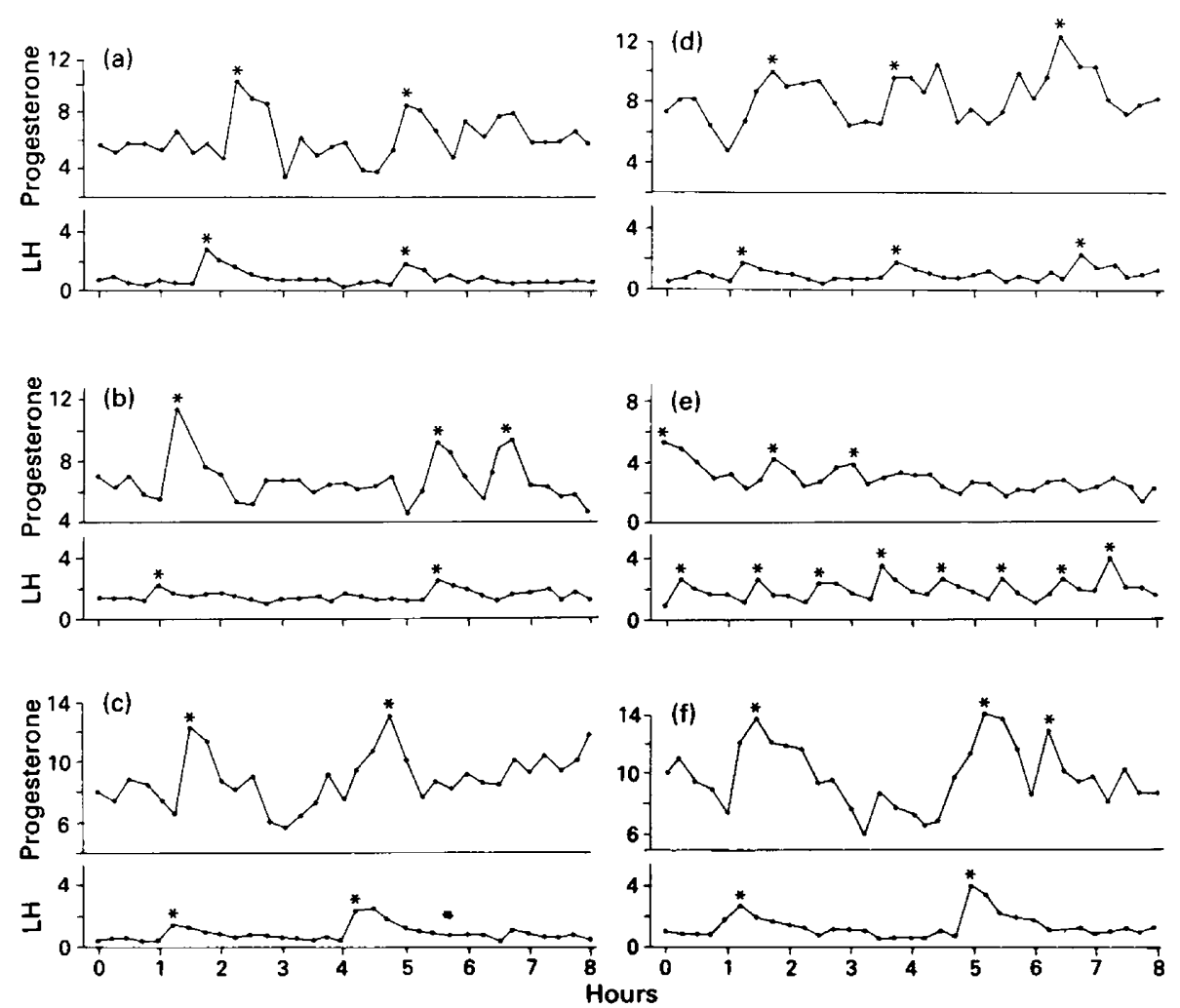

Fig. 2. Representative plasma progesterone and $\mathrm{LH}$ profiles $(\mathrm{ng} / \mathrm{ml})$ from: (a) Day-8 pregnant cow; (b) Day-14 cyclic cow; (c) Day-14 pregnant cow; (d) Day-18 pregnant cow; (e) cyclic cow on the day of luteal regression; (f) Day-21 pregnant cow. *Episodes of hormone release, as defined in the text.

was smaller and the fitted quadratic line provided no better description of the data than did a straight line. Differentiation of the fitted quadratics showed points of inflection on Days 13.1 and 13.9 for cyclic and inseminated non-pregnant cows respectively. For pregnant animals, the point of inflection in the quadratic expression occurred on Day 20.1.

Comparison of data from individual cows showed that the rate of rise of plasma progesterone concentrations between Days 3 and 9 was highly correlated between the two periods of study (i.e. in the cycle and after artificial insemination with live semen: $r=0.845, P<0.01$ ). Similarly, mean plasma progesterone concentrations between Days 14 and 18 of the two periods of study were also correlated $(r=0.77, P<0.05)$. Neither the rate of rise between Days 3 and 9 nor the mean value between Days 14 and 18 were related to the eventual success of the insemination.

\section{LH and progesterone episodes}

Representative daily plasma LH and progesterone profiles from cows on the 8th, 14th, 18th and 21 st days of pregnancy, from the 14th day of the cycle and from the day of luteal regression are illustrated in Fig. 2(a-f). There was a statistically significant interaction between day and pregnancy status with respect to LH episode frequency $(P<0.01)$. This was mainly due to the fact that, as expected, non-pregnant cows had a higher frequency of LH episodes on the day of luteal regession $(6 \cdot 10 \pm 0 \cdot 61)$ than on other days (overall mean: $2 \cdot 88 \pm 0 \cdot 09)$. There was also a tendency for the frequency of LH episodes to decline between Days $6(3.00 \pm 0.29)$ and $21(2 \cdot 50 \pm 0 \cdot 18)$ in pregnant cows. The amplitude of LH episodes showed no significant differences between days, 


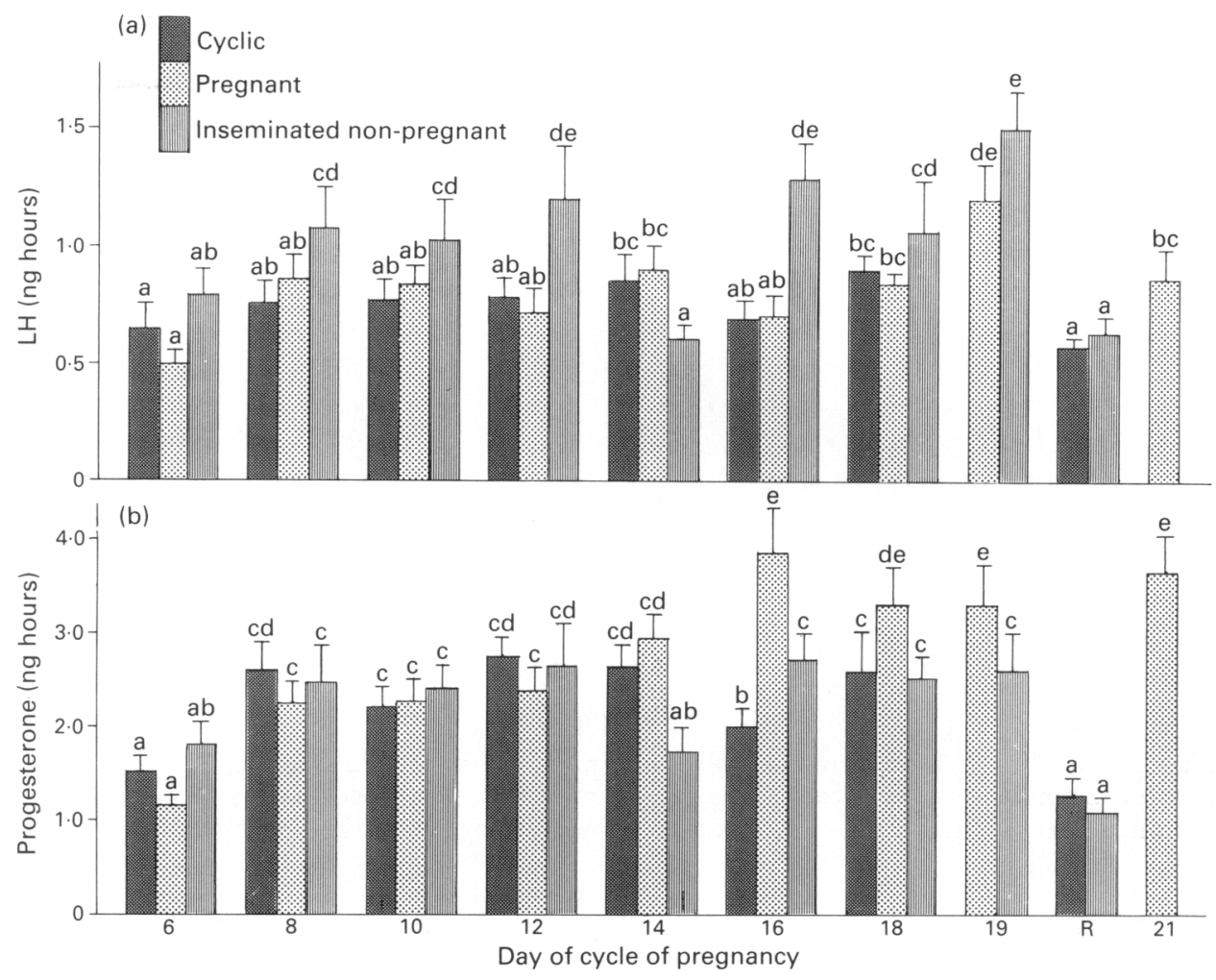

Fig. 3. Mean ( \pm s.e.m.) area under curve of (a) LH and (b) progesterone episodes of cyclic $(\mathrm{N}=12)$, pregnant $(\mathrm{N}=10)$ and inseminated non-pregnant $(\mathrm{N}=6)$ cows. $\mathrm{R}=$ the day of luteal regression in cyclic and inseminated non-pregnant cows. Bars sharing a common letter are not significantly different from each other $(P>0.05)$.

but values for inseminated non-pregnant cows were consistently greater than those of cyclic or pregnant animals $(P<0.001)$. Similarly, the area under the curve of LH episodes was greater in inseminated non-pregnant cows $(P<0.001)$ than in other groups (see Fig. 3a). However, there was no other consistent trend in the data. The frequency of progesterone episodes was not significantly different between days or groups, but followed a trend similar to that of LH episode frequency.

An overall comparison of the mean frequency of LH and progesterone episodes was made in all cows over the period between Days 8 and 18. The frequency of LH episodes was lower than that of progesterone $(2.76 \pm 0.08$ and $3.25 \pm 0.09 / 8 \mathrm{~h}$, respectively; $P<0.001)$. Generally, episodes of $\mathrm{LH}$ and progesterone were synchronized (see Fig. 2), but occasionally progesterone episodes occurred that were not accompanied by an LH episode. There were no significant differences between groups of cows or days in the interval between peak concentrations of LH episodes and either the onset or peak of progesterone episodes.

Of several measurements made on the magnitude of progesterone episodes, those of maximum amplitude and area under the curve proved the most useful. There were significant differences in day/pregnancy status groups for the mean area under the curve of each episode $(P<0.01)$ and for the absolute maximum amplitude of each episode $(P<0.01)$. These findings are illustrated in Figs 3(b) and 4. For both measurements, in all groups of animals, there was a significant increase between Days 6 and 8 . Following this, a different pattern was shown by cyclic and inseminated non-pregnant cows on the one hand and by pregnant cows on the other. In the former groups, there 


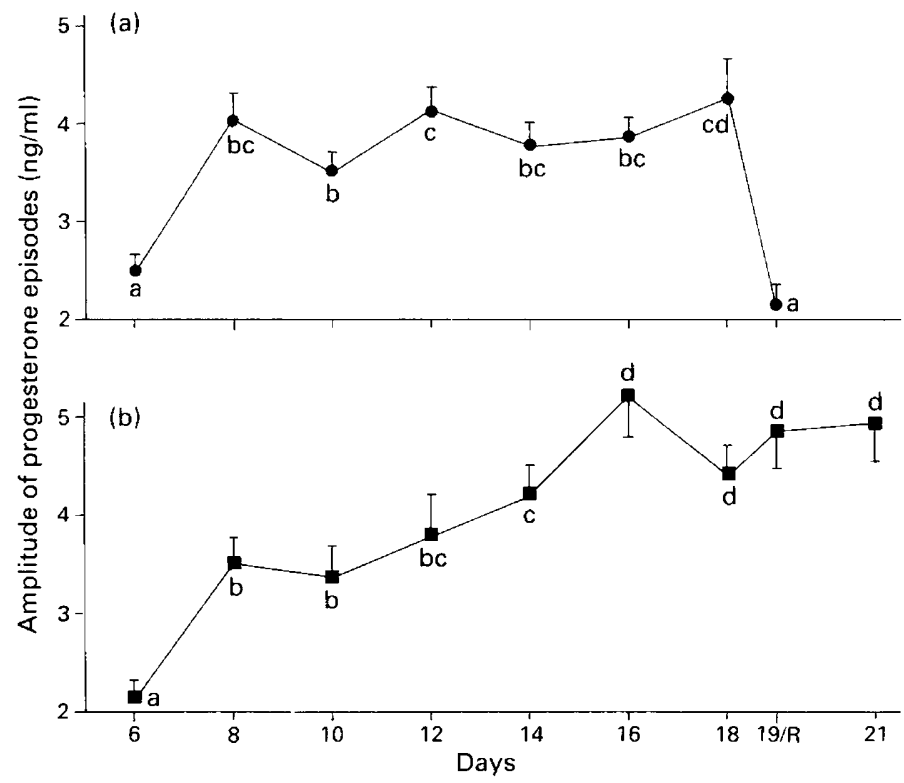

Fig. 4. Mean ( \pm s.e.m.) maximum amplitude of progesterone episodes for (a) cyclic $(N=12)$ and (b) pregnant $(\mathrm{N}=10)$ cows. $\mathrm{R}=$ the day of luteal regression in cyclic animals. Points sharing a common letter are not significantly different from each other $(P>0.05)$.

was little change in values of either parameter between Days 8 and the day before luteal regression (Day 18 for cyclic animals, Day 19 for inseminated non-pregnant cows), although values on Day 10 were lower than on Days 12 and 18. On the day of luteal regression, a marked decline in episode amplitude occurred, to values that were not significantly different from those on Day 6. By contrast, the trend in pregnant cows was for a continual increase to occur in all measures between Days 8 and 21 , although maximum values actually occurred on Day 16. This observation was quantified using regression analysis. Regression lines describing the changes in progesterone episode amplitude with day were calculated separately for each group of cows over the period between Days 8 and 18. There was no correlation between day and progesterone episode amplitude for cyclic and inseminated non-pregnant cows, nor were the regression lines of amplitude upon day significantly different from zero:

cyclic: Days $8-18, p=3 \cdot 716+0.0149 t$ (N.S.)

inseminated, not pregnant: Days $8-18, p=2 \cdot 828-0.0274 t$ (N.S.)

where $p=$ progesterone concentration $(\mathrm{ng} / \mathrm{ml})$ and $t=$ time, i.e. days after the LH surge.

For pregnant animals, however, analysis of deviance showed that the slope, but not the intercept term of the regression line, was significantly different both from those of non-pregnant cows $(P<0.001)$ and from zero $(P<0.01)$, i.e. showing that there was an increase in progesterone episode amplitude as pregnancy advanced:

$$
\text { pregnant: Days } 8-18, p=2 \cdot 049+0 \cdot 1562 t(P<0 \cdot 01) \text {. }
$$

A further comparison between the regression lines for pregnant cows over Days 8 to 18 and 8 to 21 , made to determine whether episode amplitude continued to increase after Day 18, revealed no significant difference. This indicated that an increase occurred over the whole period of study. A 


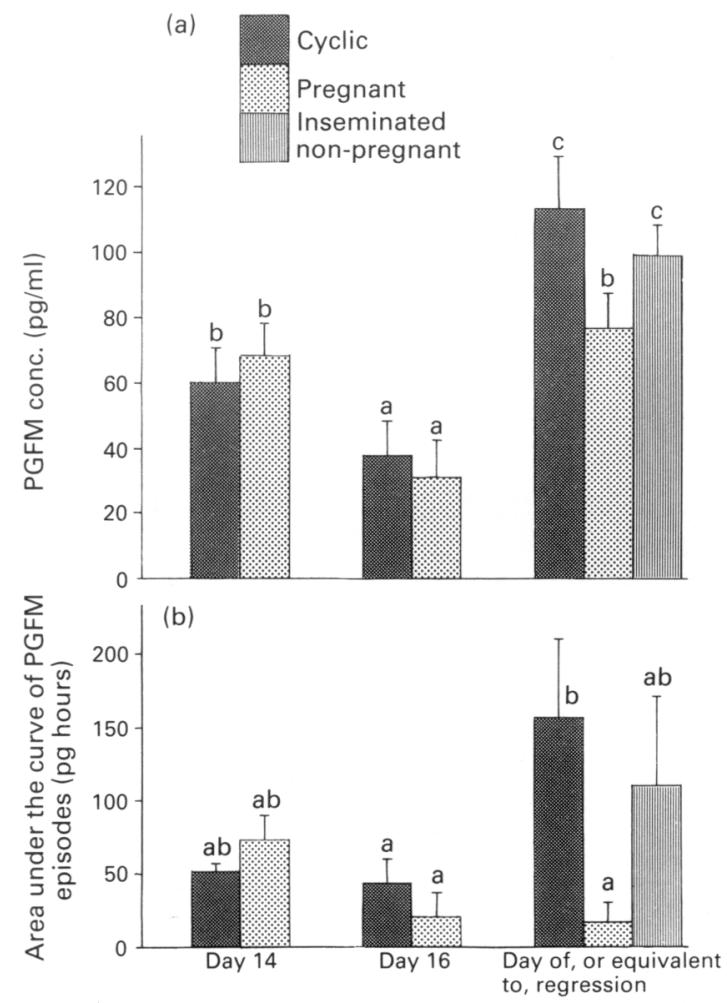

Fig. 5. Mean ( \pm s.e.m.) daily plasma concentration of PGFM (a) and area under the curve of episodes of secretion of PGFM (b), for cyclic, pregnant and inseminated non-pregnant cows. Bars sharing a common letter are not significantly different from each other $(P>0.05)$. Data from inseminated non-pregnant cows are included only for the day of luteal regression. See text for numbers of animals in each group.

similar relationship was also found between the area under the curve of progesterone episodes and day.

In addition, pregnant cows showed maximum values of progesterone episode amplitude, area under the curves of episodes and mean daily progesterone concentrations on Day 16 (see Figs 1 , 3 (b) and 4). All values were significantly higher than in cyclic animals at the equivalent time $(P<0.05)$.

\section{Plasma PGFM concentrations}

Mean daily plasma PGFM concentrations were higher in cyclic and inseminated non-pregnant cows on the day of luteal regression than in cows on the equivalent day of pregnancy $(P<0.05)$, or in cyclic or pregnant cows in Day 14 or $16(P<0.05)$. However, values in pregnant cows on the day equivalent to that of regression, and in cyclic and pregnant cows on Day 14, were greater than on Day $16(P<0.05$; see Fig. 5a). Differences in episode frequency were not significant, but showed a trend towards a greater number of small episodes on Day $14(2 \cdot 00 \pm 0 \cdot 30)$ than on other days (Day 16: $0.63 \pm 0.25$, day of regression: $0.75 \pm 0.21$ ). Conversely, the area under the curve of episodes was greater on the day of luteal regression than on other days $(P<0.05$; Fig. 5b).

Representative plasma PGFM and progesterone profiles for the day of luteal regression in a cyclic cow, and in the inseminated non-pregnant cow undergoing luteolysis by Day 21 , are illustrated in Fig. 6(a,d). The profile from a pregnant animal for the day of expected luteolysis is given 

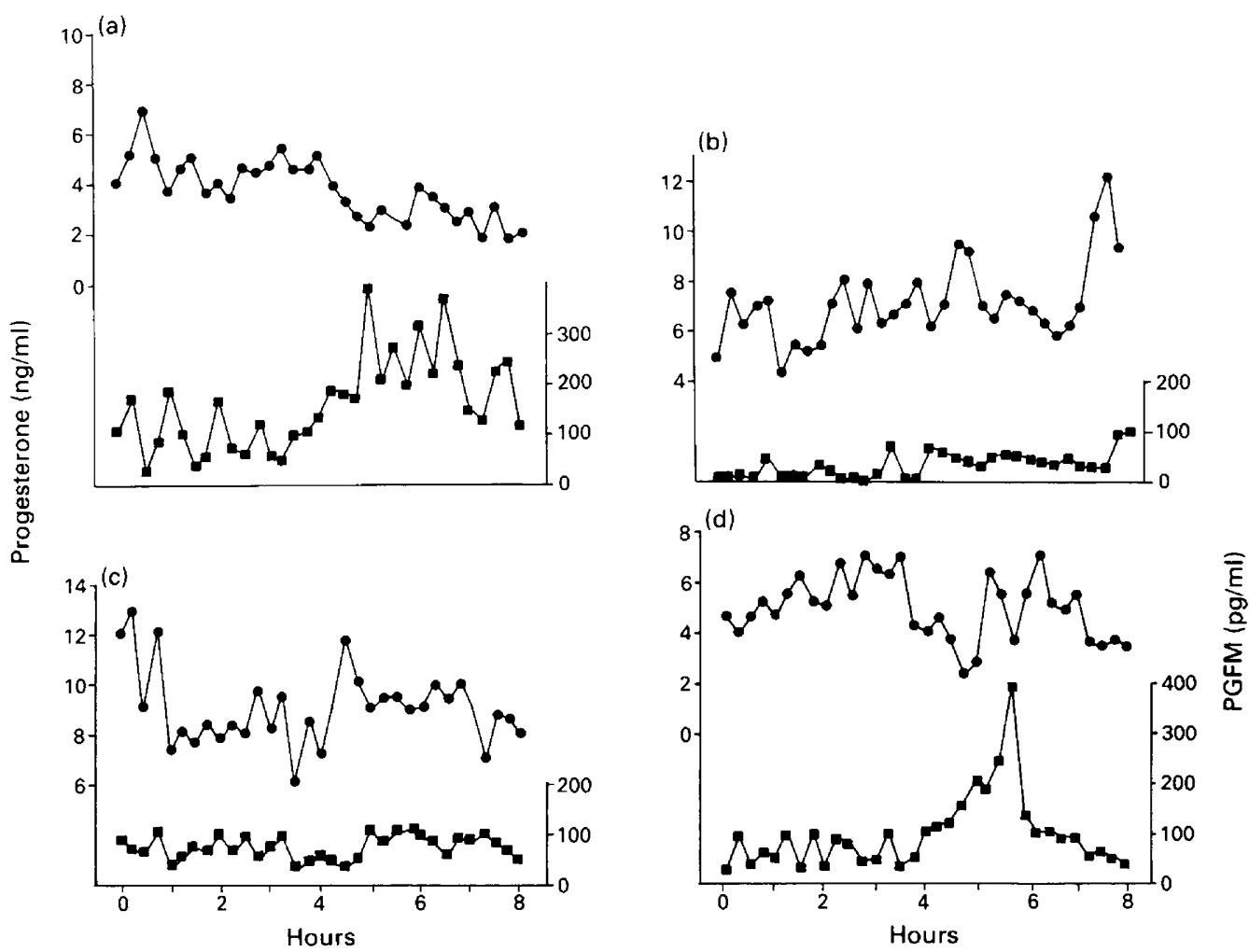

Fig. 6. Representative plasma PGFM profiles from: (a) cyclic cow on the day of luteal regression; (b) pregnant cow on the day of expected luteal regression; (c) cow, with an active corpus luteum on Day 28, but not pregnant on Day 42; (d) cow that was inseminated but not pregnant, on the day of luteal regression. The progesterone profiles from these animals are also shown for reference. Progesterone, PGFM.

in Fig. 6(b) and the profile from a cow which had maintained luteal function on Day 28, but was not pregnant by Day 42 is shown in Fig. 6(c). It is likely that this animal had conceived, but underwent embryonic mortality after the time of the maternal recognition of pregnancy signal.

\section{Discussion}

The results obtained from this study, in which frequent blood samples were collected over an 8-h period on each day during the oestrous cycle and early pregnancy, are directly comparable with only a few other reports in the literature. Although several studies have examined the oestrous cycle (e.g. Rahe et al., 1980; Walters et al., 1984; Schallenberger et al., 1985b), only Schallenberger et al. (1989) have reported on progesterone profiles from early pregnancy. Two other reports have been confined to later stages of gestation (Schallenberger et al., 1985a; Procknor et al., 1986).

The present findings indicate that no early increase in mean daily progesterone concentration occurs in pregnant compared to cyclic cows. No divergence of concentrations occurred until Day 16 and the difference which did arise was not sustained until after Day 18. Similar results were reported by Shemesh et al. (1968), Robertson \& Sarda (1971), Sreenan \& Diskin (1983) and Roche et al. (1985), none of whom found differences before Day 16. The results are thus in contrast to those of Erb et al. (1976), Lukaszewska \& Hansel (1980) and Hansel (1981), all of whom found higher values on or before Day 10 of pregnancy than of the cycle. The present results therefore 
support the suggestion (see Sreenan \& Diskin, 1983) that neither the concentration of progesterone per se, nor the rate of rise of its concentration to Day 10, has a critical effect in determining the success of establishment of pregnancy.

Reasons for the differing results between investigations of plasma progesterone concentrations are not clear, although it is possible that discrepancies could stem from the relatively low frequency of sample collection in the earlier studies. As progesterone episodes have a higher amplitude in early pregnancy than the cycle (see Fig. 4), apparent differences could arise from those samples randomly collected during periods of episodic rather than basal secretion.

The use of regression analysis to define trends in luteal function indicated that in the mid-luteal phase of cyclic and inseminated non-pregnant cows the change in progesterone concentrations with time was best described by a quadratic relationship. This infers that luteal function had reached a maximum and started to decline before the onset of definitive luteolysis (on Day 17-19; Shemesh et al., 1968). Pope et al. (1969) reported a similar conclusion from plasma progesterone profiles, as did Bulman \& Lamming (1978) and Diskin \& Sreenan (1986), using milk progesterone. Lamming et al. (1989), using regression analysis of milk progesterone profiles from large numbers of cows, also showed maximum concentrations in non-pregnant cows at around Day 13 . No such inflection occurred in pregnant cows during the period of study, indicating the likelihood that luteal function increased steadily over the first 21 days of pregnancy.

Other results from the present experiment suggest that the corpus luteum of pregnancy exhibits major functional differences from that of non-pregnant animals. These are unlikely to be due to differences in LH support, as the frequency of LH episodes tended to decline after Day 14 in pregnant animals, in the absence of any associated increase in episode magnitude (see Fig. 3). Furthermore, despite having consistently higher LH concentrations $(P<0.001)$, inseminated nonpregnant cows showed no differences in progesterone values from cyclic animals. This implies that either the inseminated cows had corpora lutea with a reduced ability to respond to $\mathrm{LH}$, or that other factors existed in these cows to affect LH secretion (e.g. oestrogen:progesterone ratio). It was also concluded from other studies of early (Little et al., 1982; Roche et al., 1985) and later (Schallenberger et al., 1985a; Procknor et al., 1986) pregnancy that LH concentrations do not differ between cyclic and pregnant cattle. The present results therefore support the conclusion that differences in luteal function between cyclic and pregnant animals are not dependent upon differences in LH secretion pattern.

The second area of difference between cyclic and pregnant cows was in the magnitude of progesterone episodes. No increase in episode magnitude occurred in non-pregnant cows after Day 8 , while pregnant animals showed a significant increase during the period between Days 8 and 21. A similar trend towards higher episode magnitude in mid-pregnancy was recorded by Schallenberger et al. (1985a) and Procknor et al. (1986), and by Schallenberger et al. (1989) from the 32nd day of pregnancy. In explanation of this phenomenon, Procknor et al. (1986) postulated the presence of a luteotrophic agent that synergizes with $\mathrm{LH}$ in stimulating progesterone synthesis. Some evidence exists for embryonic production of luteotrophic substances, such as the proteins reported by Beal et al. (1981), Hickey et al. (1985) and Plante et al. (1985), and PGE-2 (Shemesh et al., 1979; Shelton et al., 1990). PGE-2 stimulates progesterone synthesis in dispersed bovine (Speroff \& Ramwell, 1970) and ovine (Fitz et al., 1984) luteal cells in vitro, although its action in vivo is not as clearly defined. Some in-vitro studies have also reported antagonism by PGE-2 of LH-stimulated progesterone synthesis in vitro (Thomas et al., 1978; Stouffer et al., 1979; Shelton et al., 1990).

By contrast, Schallenberger et al. (1985a) considered that larger progesterone episodes occurred due to increased luteal blood flow during pregnancy. Such an increase does occur in cows at the time of the maternal recognition of pregnancy (Ford \& Chenault, 1981), which probably explains the maxima of mean daily plasma progesterone concentrations and episode magnitude that were found in the present study on the 16th day of pregnancy (see Figs 1, 3b and 4).

Alternatively, in cyclic animals, luteal degeneration could begin before the onset of definitive luteolysis (see Lamming et al., 1989). Some evidence exists to support this hypothesis in cattle 
(Donaldson \& Hansel, 1965; Hafs \& Armstrong, 1968; Lobel \& Levy, 1968) and sheep (Deane $e t$ al., 1966), with changes in luteal blood vessels and the mitochondrial integrity and lipid content of lutein cells being the main features noted. The mechanism by which these early degenerative changes are induced in the cyclic corpus luteum has not been elucidated. However, Rothchild (1981) speculated that an equilibrium exists in the mid-luteal phase between the direct stimulation of progesterone secretion by LH and its inhibition by LH-stimulated luteal PGF-2 $\alpha$ production. This suggestion could be extended, to postulate that the differences of progesterone secretion patterns occurring in pregnant compared to non-pregnant cows are due to such a PGF-2 $\alpha$ mediated inhibition of the corpus luteum of the cycle, rather than a luteotrophic stimulation in pregnancy. The findings of Silvia \& Niswender $(1984,1986)$, that the sheep corpus luteum is less sensitive to the effects of PGF-2 $\alpha$ administration between Days 13 and 16 of pregnancy than in the cycle, support this suggestion. Likewise, the finding of the present study that progesterone episodes are of lower magnitude in cyclic than pregnant animals could be interpreted that a reduction in luteal responsiveness occurs in the cycle, perhaps also as a result of early effects of PGF- $2 \alpha$.

The analysis of the episodic secretion of PGF- $2 \alpha$, as determined by peripheral concentrations of PGFM, indicated that low-amplitude episodes of PGF release occur in cyclic and pregnant cows on Days 14 and 16. Also, pregnant cows exhibited a frequency of PGF episodes similar to that of cyclic animals on the expected day of luteolysis, although the amplitude and area under the curve is much lower. Thus, by the expected time of luteolysis, it is clear that uterine secretion of PGF- $2 \alpha$ had been inhibited in pregnant cows (see Figs 5 and 6), whereas high amplitude episodes occur in nonpregnant animals. It therefore appears that luteolysis could be initiated by the effects of low amplitude uterine PGF-2 $\alpha$ secretion occurring on Days 14 and 16 and possibly by luteal PGF-2 $\alpha$ secretion, as suggested by Rothchild (1981). The reduction of luteal sensitivity to PGF-2 $\alpha$ that occurs in pregnancy (see Silvia \& Niswender, 1986) could thus prevent such an initiation of luteolysis and suppress the high-amplitude PGF- $2 \alpha$ secretion that is characteristic of irreversible luteolysis.

We thank Mrs M. Foxcroft, Mr J. C. Starrit and Mr R. M. Walker for technical assistance and Dr Hilary Dobson for the PGFM antiserum. This study received financial support from the D. R. Melrose Memorial Trust Fund (T.J.P.) and the A.F.R.C.

\section{References}

Alam, M.G.S. \& Dobson, H. (1986) Effects of various veterinary procedures on plasma concentrations of cortisol, luteinizing hormone and prostaglandin $\mathrm{F}-2 \alpha$ metabolite in the cow. Vet. Rec. 118, 7-10.

Beal, W.E., Lukaszewska, J.H. \& Hansel, W. (1981) Luteotrophic effects of bovine blastocysts. J. Anim. Sci. 52, 567-574.

Bloomfield, G.A., Morant, S.V. \& Ducker, M.J. (1986) A survey of reproductive performance in dairy herds. Characteristics of the patterns of progesterone concentrations in milk. Anim. Prod. 42, 1-10.

Bulman, D.C. \& Lamming, G.E. (1978) Milk progesterone levels in relation to conception, repeat breeding and factors influencing acyclicity in dairy cows. $J$. Reprod. Fert. 54, 447-458.

Deane, H.W., Hay, M.F., Moor, R.M., Rowson, L.E.A. \& Short, R.V. (1966) The corpus luteum of the sheep: relationships between morphology and function during the oestrous cycle. Acta endocr., Copenh. 51, 245-263.

Diskin, M.G. \& Sreenan, J.M. (1986) Progesterone and embryo survival in the cow. In Embryonic Mortality in Farm Animals, pp. 142-158. Eds J. M. Sreenan \& M. G. Diskin. Martinus Nijhoff, Dordrecht.
Donaldson, L.E. \& Hansel, W. (1965) Histological study of bovine corpora lutea. J. Dairy Sci. 48, 905-909.

Erb, R.E., Garverick, H.A., Randel, R.D., Brown, B.L. \& Callahan, C.J. (1976) Profiles of reproductive hormones associated with fertile and non-fertile inseminations of dairy cows. Theriogenology 5 , $227-242$.

Fitz, T.A., Hoyer, P.B. \& Niswender, G.D. (1984) Interactions of prostaglandins with subpopulations of ovine luteal cells. 1. Stimulatory effects of prostaglandins E-1, E-2 and I-2. Prostaglandins 28, 119-126.

Ford, S.P. \& Chenault, J.R. (1981) Blood flow to the corpus luteum-bearing ovary and ipsilateral uterine horn during the oestrous cycle and early pregnancy. $J$. Reprod. Fert. 62, 555-562.

Gadsby, J.E., Heap, R.B., Henville, A. \& Laing, J.A. (1974) A semi-automated technique for the estimation of progesterone in cow's milk and its application to pregnancy diagnosis. J. Physiol., Lond. 242, $3 \mathrm{P}-5 \mathrm{P}$, abstr.

Glencross, R.G. \& Pope, G.S. (1981) Concentrations of estradiol-17 $\beta$ in the plasma of dairy heifers before and after cloprostenol-induced and natural luteolysis 
and during early pregnancy. Anim. Reprod. Sci. 4, 93-106.

Glencross, R.G., Abeywardene, S.A., Corney, S.J. \& Morris, H.S. (1981) The use of oestradiol-17 $\beta$ antiserum covalently coupled to sepharose to extract oestradiol-17 $\beta$ from biological fluids. J. Chromat. 223, $193-197$.

Goodman, R.L. \& Karsch, F.J. (1980) Pulsatile secretion of luteinizing hormone: differential suppression by ovarian steroids. Endocrinology 107, 1286-1290.

Hafs, H.D. \& Armstrong, D.T. (1968) Corpus luteum growth and progesterone synthesis during the bovine estrous cycle. J. Anim. Sci. 27, 134-141.

Hansel, W. (1981) Plasma hormone concentrations associated with early embryo mortality in heifers. $J$. Reprod. Fert., Suppl. 30, 231-239.

Haresign, W., Foster, J.P., Haynes, N.B., Crighton, D.B. \& Lamming, G.E. (1975) Progesterone levels following treatment of seasonally anoestrous ewes with synthetic LH-releasing hormones. J. Reprod. Fert. 43, 269-279.

Henricks, D.M., Lamond, D.R., Hill, J.R. \& Dickey, J.F. (1971) Plasma progesterone concentrations before mating and in early pregnancy in the beef heifer. $J$. Anim. Sci. 33, 450-454.

Hickey, G.J., Walton, J.S., Harper, H. \& Hansel, W. (1985) Partial purification of a luteotropic substance from allantoic fluids of 28-37 day bovine conceptuses. Biol. Reprod. 32 (Suppl. 1), 53, abstr.

Hunter, M.G., Southee, J.A., McLeod, B.J. \& Haresign, W. (1986) Progesterone pretreatment has a direct effect on GnRH-induced preovulatory follicles to determine their ability to develop into normal corpora lutea in anoestrous ewes. J. Reprod. Fert. 76, 349-363.

Kaker, M.L., Murray, R.D. \& Dobson, H. (1984) Plasma hormone changes in cows during induced or spontaneous calvings and the early post-partum period. Vet. Rec. 115, 378-382.

Lamming, G.E., Darwash, A.O. \& Back, H.L. (1989) Corpus luteum function in dairy cows and embryo mortality. J. Reprod. Fert., Suppl. 37, 245-252.

Little, D.E., Rahe, C.H., Fleeger, J.L. \& Harms, P.G. (1982) Episodic release of LH during gestation in the cow. J. Reprod. Fert. 66, 687-690.

Lobel, B.L. \& Levy, E. (1968) Formation, development and involution of corpora lutea. Acta endocr., Copenh., Suppl. 132, 35-51.

Lukaszewska, J. \& Hansel, W. (1980). Corpus iuteum maintenance during early pregnancy in the cow. $J$. Reprod. Fert. 59, 485-493.

Plante, C., Bousquet, D., Guay, P., Gofi, A.K. \& King, W.A. (1985) Luteotrophic factor secreted by bovine embryonic tissue. Theriogenology 23, 217, abstr.

Pope, G.S., Gupta, S.K. \& Munro, I.B. (1969) Progesterone levels in the systemic plasma of pregnant, cycling and ovariectomized cows. J. Reprod. Fert. 20, 369-381

Procknor, M., Dachir S., Owens, R.E., Little, D.E. \& Harms, P.G. (1986) Temporal relationship of the pulsatile fluctuation of luteinizing hormone and progesterone in cattle: a time series cross-correlation analysis. J. Anim. Sci. 62, 191-198.

Rahe, C.H., Owens, R.E., Fleeger, J.L., Newton, H.J. \& Harms, P.G. (1980) Pattern of plasma luteinizing hormone in the cyclic cow: dependence upon the period of the cycle. Endocrinology 107, 498-503.

Robertson H.A. \& Sarda, I.R. (1971) A very early pregnancy test for mammals: its application to the cow, sow and ewe. J. Endocr. 49, 407-419.

Roche, J.F., Ireland, J.J., Boland, M.P. \& McGeady, T.M. (1985) Concentrations of luteinizing hormone and progesterone in pregnant and non-pregnant heifers. Vet. Rec. 116, 153-155.

Rothchild, I. (1981) The regulation of the mammalian corpus luteum. Recent Prog. Horm. Res. 37, 183-283.

Schallenberger, E., Rampp, J. \& Walters, D.L. (1985a) Gonadotrophins and ovarian steroids in cattle. 2. Pulsatile changes of concentrations in the jugular vein throughout pregnancy. Acta endocr., Copenh. 108, 322-330.

Schallenberger, E., Schondorfer, A.M. \& Walters, D.L. (1985b) Gonadotrophins and ovarian steroids in cattle. 1. Pulsatile changes of concentrations in the jugular vein throughout oestrous cycle. Acta endocr., Copenh. 108, 312-321.

Schallenberger, E., Schams, D. \& Meyer, D. (1989) Sequences of pituitary, ovarian and uterine hormone secretion during the first 5 weeks of pregnancy in dairy cattle. J. Reprod. Fert., Suppl. 37, 277-286.

Shelton, K., Parkinson, T.J., Hunter, M.G., Kelly, R.W. \& Lamming, G.E. (1990) Prostaglandin E-2 as a potential luteotrophic agent during early pregnancy in cattle. J. Reprod. Fert. 90, 11-17.

Shemesh, M., Ayalon, N. \& Lindner, H.R. (1968) Early effects of conceptus on plasma progesterone level in the cow. J. Reprod. Fert. 15, 161-164.

Shemesh, M., Milaguir, F., Ayalon, N. \& Hansel, W. (1979) Steroidogenesis and prostaglandin synthesis by cultured bovine blastocysts. $J$. Reprod. Fert. 56, 181-185.

Silvia, W.J. \& Niswender, G.D. (1984) Maintenance of the corpus luteum of early pregnancy in the ewe. 3 . Differences between pregnant and non-pregnant ewes in luteal responsiveness to prostaglandin F-2a. $J$. Anim. Sci. 59, 746-753.

Silvia, W.J. \& Niswender, G.D. (1986) Maintenance of the corpus luteum of early pregnancy in the ewe. 4. Changes in luteal responsiveness to prostaglandin F-2a throughout pregnancy. J. Anim. Sci. 63, $1201-1207$.

Speroff, L. \& Ramwell, P.W. (1970) Prostaglandin stimulation of in vitro progesterone synthesis. J. clin. Endocr. Metab. 30, 345-350.

Sreenan, J.M. \& Diskin, M.G. (1983) Early embryonic mortality in the cow: its relationship with progesterone concentration. Vet. Rec. 122, 517-521.

Stouffer, R.L., Nixon, W.E. \& Hodgen, G.D. (1979) Disparate effects of prostaglandins on basal and gonadotropin-stimulated progesterone production by luteal cells isolated from rhesus monkeys during the menstrual cycle and pregnancy. Biol. Reprod. 20, 897-903.

Thatcher, W.W., Hansen, P.J., Gross, T.S., Helmer, S.D., Plante, C. \& Bazer, F.W. (1989) Antiluteolytic effects of bovine trophoblast protein-1. J. Reprod. Fert., Suppl. 37, 91-99.

Thomas, J.P., Dorflinger, L.J. \& Behrman, H.R. (1978) Mechanism of the rapid anti-gonadotropic action of 
prostaglandins in cultured luteal cells. Proc. natn. Acad. Sci. USA 75, 1344-1348.

Walters, D.L., Schams, D. \& Schallenberger, E. (1984). Pulsatile secretion of gonadotrophins, ovarian steroids and ovarian oxytocin during the luteal phase of the oestrous cycle in the cow. J. Reprod. Fert. 71, $479-491$.
Webb, R., Lamming, G.E., Haynes, N.B., Hafs, H.D. \& Manns, J.G. (1977) Response of cyclic and postpartum suckled cows to injections of synthetic LH-RH. J. Reprod. Fert. 50, 203-210.

Received 4 January 1990 